\title{
High-Performance Anticorrosive Polyester Coatings on Mild Steel in Mixed Acid Mixtures Environments
}

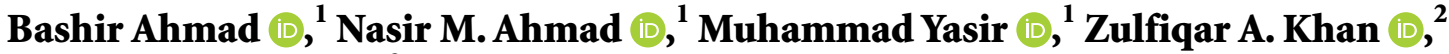 \\ and Sikander Rafiq ${ }^{3}{ }^{3}$ \\ ${ }^{1}$ Polymer Research Lab, Department of Materials Engineering, School of Chemical and Materials Engineering (SCME), \\ National University of Sciences and Technology (NUST), H-12 Sector, Islamabad 44000, Pakistan \\ ${ }^{2}$ Bournemouth University, Department of Design and Engineering, NanoCorr, Energy \& Modelling (NCEM) Research Group, \\ Dorset, Poole BH12 5BB, UK \\ ${ }^{3}$ Department of Chemical Polymer \& Composite Materials Engineering, University of Engineering \& Technology, Lahore \\ (New Campus), Pakistan
}

Correspondence should be addressed to Nasir M. Ahmad; nasir.ahmad@scme.nust.edu.pk

Received 15 April 2019; Accepted 26 August 2019; Published 19 December 2019

Academic Editor: Alexandra Muñoz-Bonilla

Copyright ( 2019 Bashir Ahmad et al. This is an open access article distributed under the Creative Commons Attribution License, which permits unrestricted use, distribution, and reproduction in any medium, provided the original work is properly cited.

\begin{abstract}
Mild steel sample was selected from acid storage tanks used in industry as a substrate, and two advanced technological polymeric resin-based coatings were developed, designated as LAM-P resin based which is LAM-P/FR coating and LAM-V resin based which is LAM-V/FR coating. These coatings were applied over steel samples by using the hand lay-up process. FTIR test was conducted to confirm complete curing, and SEM analyses were used to investigate surface morphology. A series of electrochemical tests were performed in acidic environment (mixed acid solution $56 \% \mathrm{H}_{2} \mathrm{SO}_{4}+26 \% \mathrm{HNO}_{3}+18 \% \mathrm{H}_{2} \mathrm{O}$ by weight). The results indicated successful development of LAM-P/FR and LAM-V/FR to obtain coatings with desirable characteristics such as anticorrosion, thickness, adhesion, stability, charge store and more resistance to acidic environments. EIS data for mixed acid storage media demonstrated that LAM-V/FR coating has higher strength in mixed acid solution, higher values of impedance and phase shift, higher value of $R_{\text {pore }}$, and low value of $C_{c}$, Corrosion rate percentage reduction is $96 \%$ of LAM-P/FR and $99.96 \%$ of LAM-V/FR compared to bare mild steel sample. The outcomes of this study can lead to assist in design guidelines for anticorrosive coating for industrial applications.
\end{abstract}

\section{Introduction}

Corrosion is electrochemical decay of materials and is caused by the reaction between materials and aggressive or corrosive environments. Metals are most susceptible to this type of impact because they contain free electrons and can form electrochemical cells within their structure [1]. Corrosion results in significant economic loss, and it slows down the economic growth of all countries. The annual cost of corrosion worldwide is estimated to be 2.2 trillion US dollars. National Association of Corrosion Engineers (NACE) estimated that the direct cause of corrosion in the United States was 276 billion dollars in 2014, approximately $3.1 \%$ of gross domestic product (GDP). However, by including the indirect losses of corrosion, it was estimated to exceed 1 trillion US dollars.

When sulfuric acid $\left(\mathrm{H}_{2} \mathrm{SO}_{4}\right)$ and dilute nitric acid $\left(\mathrm{HNO}_{3}\right)$ are mixed together, they became highly corrosive. Corrosion with in acid storage tank is dependent on several factors such as temperature, concentration of corrosive constituents, operational condition, and the purity of acids being used [2]. Mild steel corrosion rate in $95 \% \mathrm{H}_{2} \mathrm{SO}_{4}$ is $5-20 \mathrm{~mm}$ /year when the temperature is less than $25^{\circ} \mathrm{C}$. This depends on the material from which the tank is made and the purity of the received acid [3].

Corrosion is probably one of the most concerning issues that is faced in practical applications, thus different research strategies being added throughout the globe for the sole purpose of protecting different material from corrosion in various areas of applications. Many techniques are being used for protecting the structures from corrosion by adding corrosion inhibitors $[4,5]$, by applying cathode and anode protection [6,7], design modification, alteration with environments, and most importantly changing the material which is more corrosion resistant, for example stainless steel [8]. Application of 
various types of protective coatings is another popular method for protecting metals from aggressive corrosion reactions $[9,10]$. Researchers are continuously seeking new innovative coatings which will enhance corrosion protection of assets in conventional environments [11].

Ananda Kumar et al. [12] in 2008 studied corrosion behavior of mild steel coated with polymer and polymer-metal bilayer coating. Cyclic voltammetry technique was used to synthesize coatings, whereas EIS and potentiodynamic corrosion testing techniques were used for the study. Protection mechanism of PANI based coating acted as a protective barrier; however, there are limitations due to the porosity of PANI-based coatings. In polyaniline (PANI) metal bilayer coatings, metal nanoparticles filled porous sites of PANI and protection was better than PANI-based because of dual effect of barrier and sacrificial attributes. Also, PANI-Zn-based coating provided better protection than PANI-Ni.

Shittu et al. [13] used weight loss method to study corrosion behavior of polystyrene coated mild steel, $\mathrm{HCl}$ and $\mathrm{H}_{2} \mathrm{SO}_{4}$ testing environments. Corrosion inhibition of mild steel increased at high concentration of polystyrene but decreased with increasing time.

Syed et al. [14] studied corrosion protection of $316 \mathrm{~L}$ stainless steel by using polymers' multilayer coating; polyaniline polyacrylic acid/polyethylene mine (PANI/PAA/PEI) composite coating was prepared and coated on substrate by spin coating method. The study showed that combination of coating provided corrosion resistance required when substrate was put in $3.5 \% \mathrm{NaCl}$ environment as observed during the electrochemical measurements. Increase in corrosion resistance can be attributed to the fact that diffusion pathway of corrosion ions was increased due to multilayer structure.

Ameen Uddin Ammar et al. [15] in their study selected two nanocomposite-based coatings: one polymeric based which is PVA/PANI/FLG and the other ceramic based which is $\mathrm{TiO}_{2} / \mathrm{GO}$. Both coatings were applied on samples by using dip coating technique. Electrochemical tests were performed in sea-water and crude oil environment. EIS study showed that ceramic-based coating exhibited high values of impedance and phase shift in Bode plot, while on the other hand, the Nyquist results showed that $\mathrm{TiO}_{2} / \mathrm{GO}$ coating satisfied high values of impedance and had enhanced durability prior to degradation when compared with PVA/PANI/FLG coatings. In addition, in the case of crude oil, results were different as compared to seawater. In crude oil, PVA/PANI/FLG coated samples provided more protection compared to $\mathrm{TiO}_{2} / \mathrm{GO}$ coated samples.

In the presented work, the surface of mild steel was coated by protective polymer coatings. Mild steel customized storage tanks were fabricated and were coated with anticorrosive LAM-V/FR and LAM-P/FR coatings. Various coatings' composition was investigated including ester constituents. EIS and Tafel scan analytical techniques were employed by using Gamry potentiostatand SEM was used to determine surface morphologies.

Polymer-based composite coatings are discussed in terms of their corrosion resistance from both coating conditions and reduction in corrosion rate perspectives. LAM-P/FR corrosion rate percentage reduction was $96 \%$ and that of LAM-V/FR was $99.96 \%$ compared to bare mild steel samples.

\section{Methodology}

Anticorrosive performance of two types of polyester-based composite coatings, laminate vinyl fiber-reinforced coating and laminate palatal fiber-reinforced coating (LAM-V/FR and LAM-P/FR), was studied and compared when these were subjected to acidic environment. Anticorrosive behavior of mild steel in acidic medium has been used as benchmark.

Figure 1 shows material and chemical reaction involved in the preparation of LAM-V/FR and LAM-P/FR coatings. In first coating, unsaturated and uncured polymer $\mathrm{V}$ resin was used for coating on mild steel tanks. It happened when it reacts with monomer styrene in the presence of MEKP and formed a cured composite. In second coating, unsaturated P-4 resin was used for coating, and it reacts with styrene in the presence of MEKP and formed coating on mild steel as chemical reactions shown in Figure 1.

Two types of coatings (LAM-V/FR and LAM-P/FR) have been investigated in an acidic corrosive environment in which samples of both coatings along with a bare metal are tested and compared. The order of testing can be seen in Figure 2 . The first step involves the preparation of samples; then, coating was synthesized on mild steel for the confirmation of curing and FTIR analysis was carried out. To study the effectiveness of coating, EIS analysis was performed. Finally, a comparison between the results of coated and uncoated mild steel was carried out and it was concluded that the coating prevents mild steel from corrosion and increases the life of acid tanks.

\subsection{Sample Preparation}

2.1.1. Preparation of Mild Steel Sample. BS436043A steel plates were used to produce various types of steel bolts, steel welds, storage tanks, and other structural components with the following compositions [3]. Table 1 demonstrates the composition of mild steel; that is, it consists of $0.25 \%$ of carbon (C), $0.50 \%$ of silica $(\mathrm{Si}), 1.6 \%$ of manganese $(\mathrm{Mn}), 0.05 \%$ of phosphorous (P), $0.05 \%$ of sulfur (S), and $0.20-0.35 \%$ of copper $(\mathrm{Cu})$.

2.1.2. Preparation of $L A M-V / F R$ Coating. LAM-V/FR is a two-component fiber-reinforced, trowel and brush applied polyester resin-based coating system. Due to multiple layers of the overlapping fiber, an extremely low water vapor permeation rate is achieved. Excellent permeation resistance is a feature of this coating, ensuring a long service life. This coating/lining system consists of jell coat and two coats of LAM-V resin applied by trowel and brush at a target thickness of $40 \mathrm{~mm}$. Higher thickness and additional layers may be recommended for specific operating conditions. Table 2 shows the thickness of coating. It reveals that primary coating of binder has thickness of $2-5 \mathrm{~mm}$, while on the other hand, LAM-V resin along with fiber-reinforced material has a thickness of $60-80 \mathrm{~mm}$.

First, the surface contaminations were removed by using acetone to confirm adhesion of the new LAM-V/FR-coating system. LAM-V resins contain 30-50 wt\% monomers [16, 17]. 


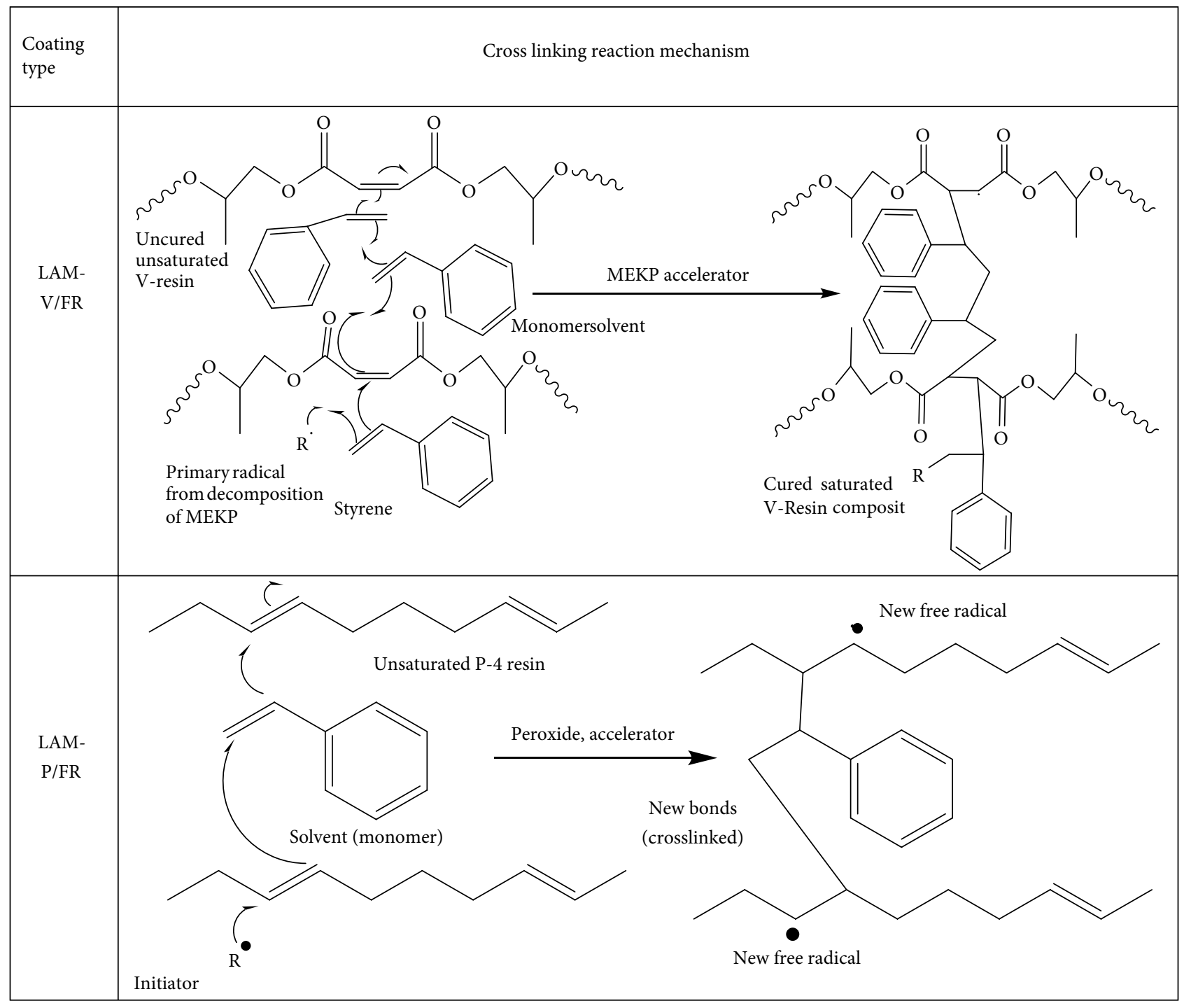

FIGURE 1: Reactions involved in LAM-V/FR and LAM-P/FR coatings.

LAM-V resins reacted by free-radical copolymerization reaction with catalyst. Figure 3 shows a mechanism of the network formed by the free-radical cross-linking reaction. Peroxide (catalyst) and accelerator are added to the LAM-V resin that was already dissolved in monomer/solvent (act as a cross-linking agent) in various mixing ratios. Additionally, pigment solution P1 was added to either the basecoat or topcoat resin. This will provide alternating colored layers, which assures complete coverage. Fiber mat was used as a reinforcement material. The primer and lining components were calculated, and the amounts added were best for curing of these pre-measured quantities including polymer resin and hardener as layer scheme shown in Figure 3.

2.1.3. Preparation of $L A M-P / F R$ Coating. LAM-P resin is an unsaturated polymer that is already dissolved in solvent to reduce its viscosity and take part in cross-linking polymerization reaction. The resin used here has a medium reactivity and a medium viscosity [18]. This is because the
P-resin dissolved in styrene and acts as a monomer as well as a solvent; therefore, the viscosity reduces to medium. Table 3 shows the thickness of coating. It reveals that primary coating of binder has thickness of $2-5 \mathrm{~mm}$, while on the other hand, LAM-P-4 resin along with fiber-reinforced material has a thickness of $60-80 \mathrm{~mm}$.

2.2. Corrosion Testing Procedure. After the synthesis and application of coatings on the sample, electrochemical test was conducted. Electrochemical impedance spectroscopy (EIS) was performed. EIS for coated metal substrate measures two phenomena which show deterioration of the organic polymer coating when in contact within electrolyte and also the increases in corrosion rate of the substrate due to the deterioration of the coating and impact electrolyte impact [19].

Figure 4 shows the schematic of EIS test setup. A three-electrode potentiostat system was used for this study [20,21].

In the above setup, mild steel is used as a working electrode, graphite as a counter electrode, and silver-silver 


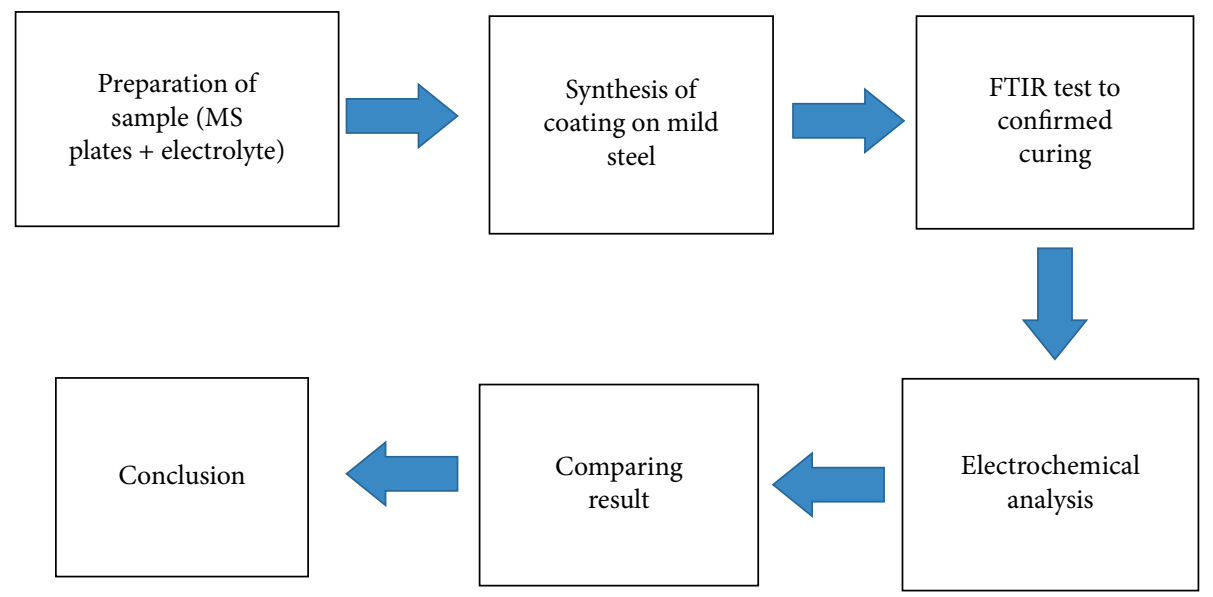

FIGURE 2: Flow chart showing the order of testing.

TABLE 1: Chemical composition.

\begin{tabular}{lcccccc}
\hline Grade & \multicolumn{5}{c}{ Chemical composition (\%) } \\
\hline \multirow{2}{*}{$43 \mathrm{~A}$} & $\mathrm{C}$ & $\mathrm{Si}$ & $\mathrm{Mn}$ & $\mathrm{P}$ & $\mathrm{S}$ & $\mathrm{Cu}$ \\
& 0.25 & 0.50 & 1.6 & 0.05 & 0.05 & $0.20 / 0.35$ \\
\hline
\end{tabular}

TABLE 2: Shows the different layers of LAM-V/FR coating.

\begin{tabular}{lc}
\hline Layer & Thickness \\
\hline Binder primary coat & $2-5 \mathrm{~mm}$ \\
LAM-V resin + fiber reinforce layer & $60-80 \mathrm{~mm}$ \\
\hline
\end{tabular}

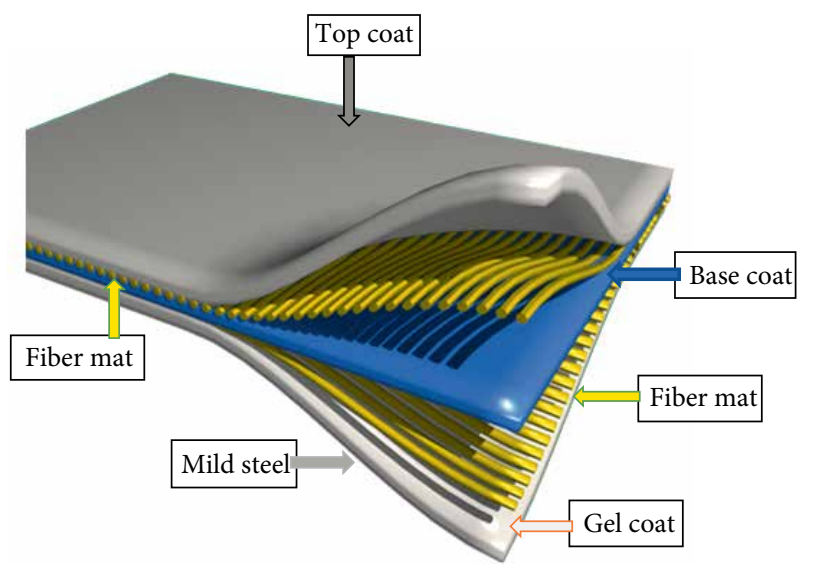

Figure 3: Basecoat and topcoat are reinforced with fiber mat.

chloride has been used as a reference electrode. Mixed acid is used as an electrolyte and has a weight percentage composition of $56 \% \mathrm{H}_{2} \mathrm{SO}_{4}, 26 \% \mathrm{HNO}_{3}$, and $18 \% \mathrm{H}_{2} \mathrm{O}$. LAM-V/FR and LAM-P/FR coatings were developed on mild steel and were used as a barrier between mild steel and electrolyte. A glass cell setup was fixed over the coated mild steel sample with the help of sealant [22].
TABLE 3: Thickness of different layers of LAM-P/FR coating.

\begin{tabular}{lc}
\hline Layer & Thickness \\
\hline Binder layer & $2-5 \mathrm{~mm}$ \\
LAM-P resin + fiber mat layer & $60-80 \mathrm{~mm}$ \\
\hline
\end{tabular}

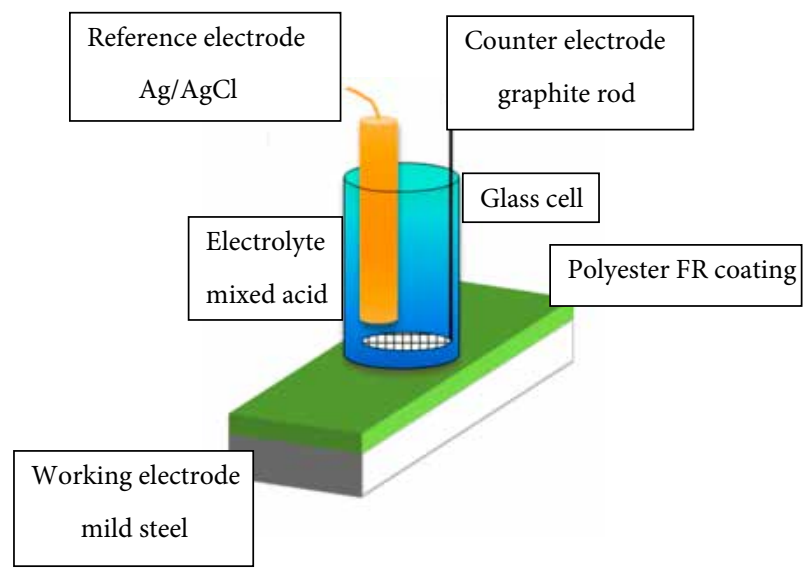

FIGURE 4: Experimental setup of EIS.

TABLE 4: Chemical compositions of electrolyte solution.

\begin{tabular}{lcccc}
\hline $\begin{array}{l}\text { Acid } \\
\text { composition }\end{array}$ & $\mathrm{H}_{2} \mathrm{SO}_{4}(\%)$ & $\mathrm{HNO}_{3}(\%)$ & $\mathrm{HNO}_{2}(\%)$ & $\mathrm{H}_{2} \mathrm{O}(\%)$ \\
\hline $\begin{array}{l}\text { High nitro } \\
\text { cellulose }\end{array}$ & 56 & 26 & 0.60 & 17.40 \\
\hline
\end{tabular}

EIS data are further analyzed by using fitting models; these models are used according to coating and environment types. The following information about tested material (metals, coatings) and environment is generated; (i) electrolyte resistance, (ii) double-layer capacitance, (iii) polarization resistance, (iv) resistance to charge transfer, and (v) coating capacitance. 


\begin{tabular}{|c|c|c|c|c|c|}
\hline Bode & Nyquist & $\begin{array}{l}\text { Experimental } \\
\text { setup }\end{array}$ & $\begin{array}{c}\text { Experimental } \\
\text { notes }\end{array}$ & $\begin{array}{c}\text { Open circuit } \\
\text { voltage }\end{array}$ & $\begin{array}{c}\text { Hardware } \\
\text { setting }\end{array}$ \\
\hline DC voltage $(\mathrm{v})$ & \multicolumn{5}{|l|}{0} \\
\hline $\begin{array}{l}\text { AC voltage } \\
(\mathrm{mv} r \mathrm{rm})\end{array}$ & \multicolumn{5}{|l|}{20} \\
\hline Test identifier & \multicolumn{5}{|c|}{ Potentiostatic EIS } \\
\hline Date & \multicolumn{5}{|l|}{$04 / 20 / 17$} \\
\hline Time & \multicolumn{5}{|l|}{ 17:10:09 } \\
\hline Initial freq. $(\mathrm{Hz})$ & \multicolumn{5}{|l|}{100000} \\
\hline Final freq. $(\mathrm{Hz})$ & \multicolumn{5}{|l|}{0.2} \\
\hline Points/decade & \multicolumn{5}{|l|}{10} \\
\hline Area $\left(\mathrm{cm}^{2}\right)$ & \multicolumn{5}{|l|}{9} \\
\hline Conditioning & off & \multicolumn{2}{|l|}{15 Time (s) } & \multicolumn{2}{|c|}{$0 \mathrm{E}(\mathrm{v})$} \\
\hline Init. delay & on & 10 Time (s) & & 0 stab. & Vs) \\
\hline Open circuit (v) & \multicolumn{5}{|c|}{-0.802706} \\
\hline
\end{tabular}

FIGURE 5: Data entry in the software of Gamry framework and Echem analyst.

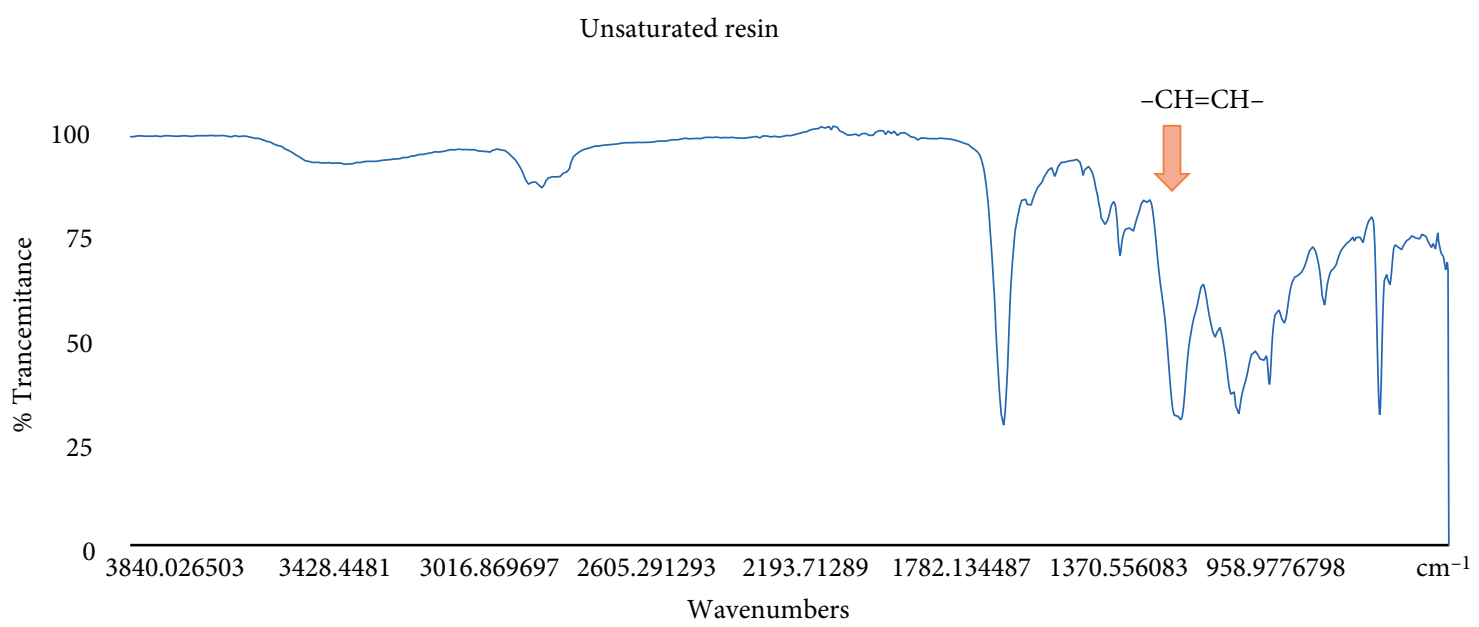

FIGURE 6: Spectral analysis of unsaturated polyester resin.

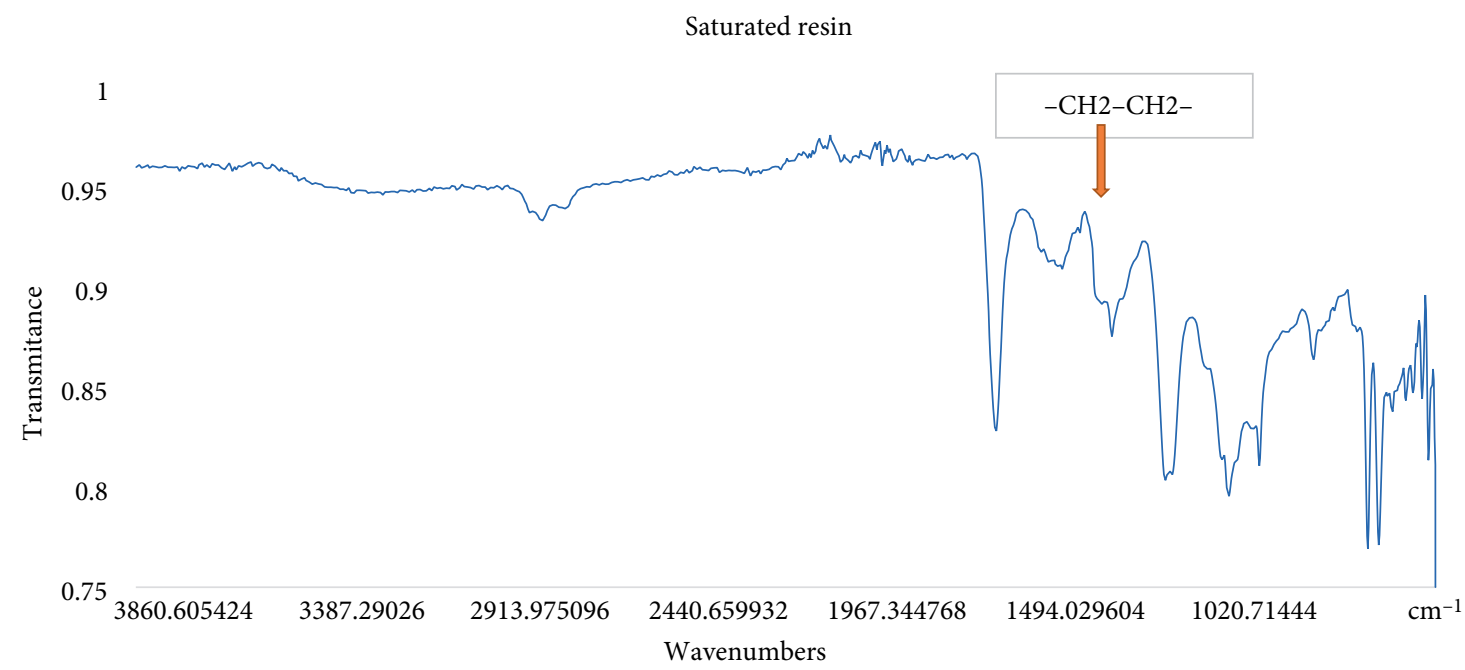

FIGURE 7: IR spectra of fiber-reinforced polymer composite.

Acidic environment/electrolyte was used for this study. Acidic composition for which EIS data have been acquired is provided in Table 4. It shows the composition of mixed acid that was stored in the mild steel tanks, and the acid composition is
$56 \% \mathrm{H}_{2} \mathrm{SO}_{4}, 26 \% \mathrm{HNO}_{3}, 0.60 \% \mathrm{HNO}_{2}$, and $17.40 \% \mathrm{H}_{2} \mathrm{O}$. This composition was taken as an electrolyte in electrochemical cell.

After data entry in Gamry software, shown in Figure 5, in which initial frequency was set at $100000 \mathrm{~Hz}$, final frequency 
0 month dip
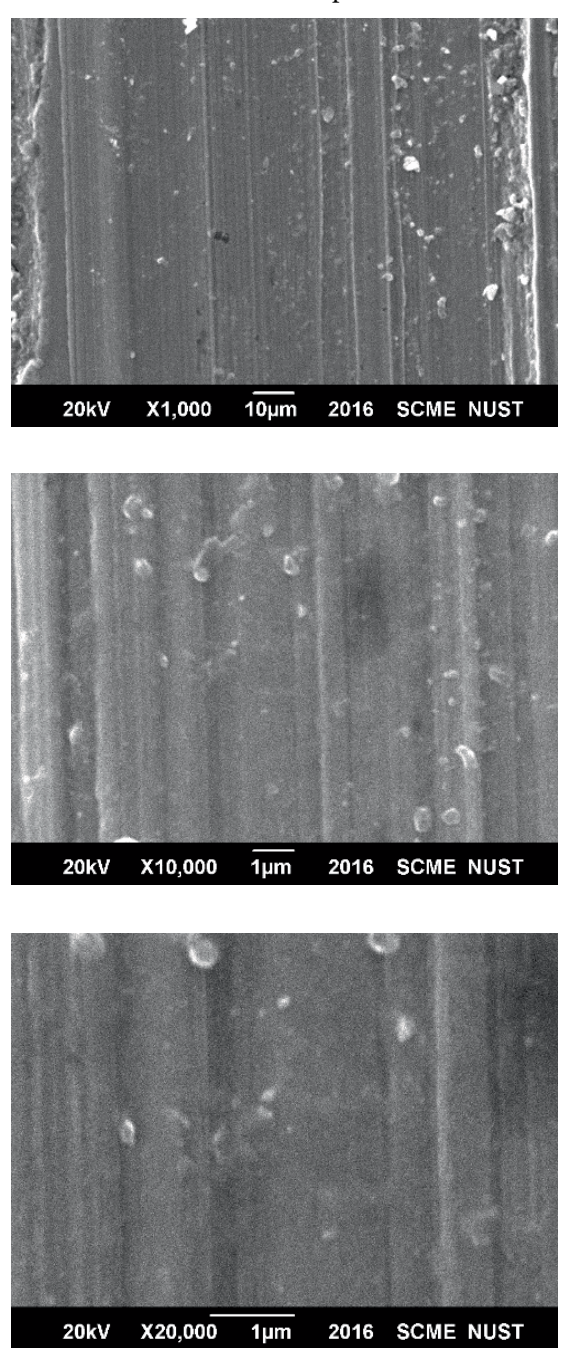

After 2 month dip
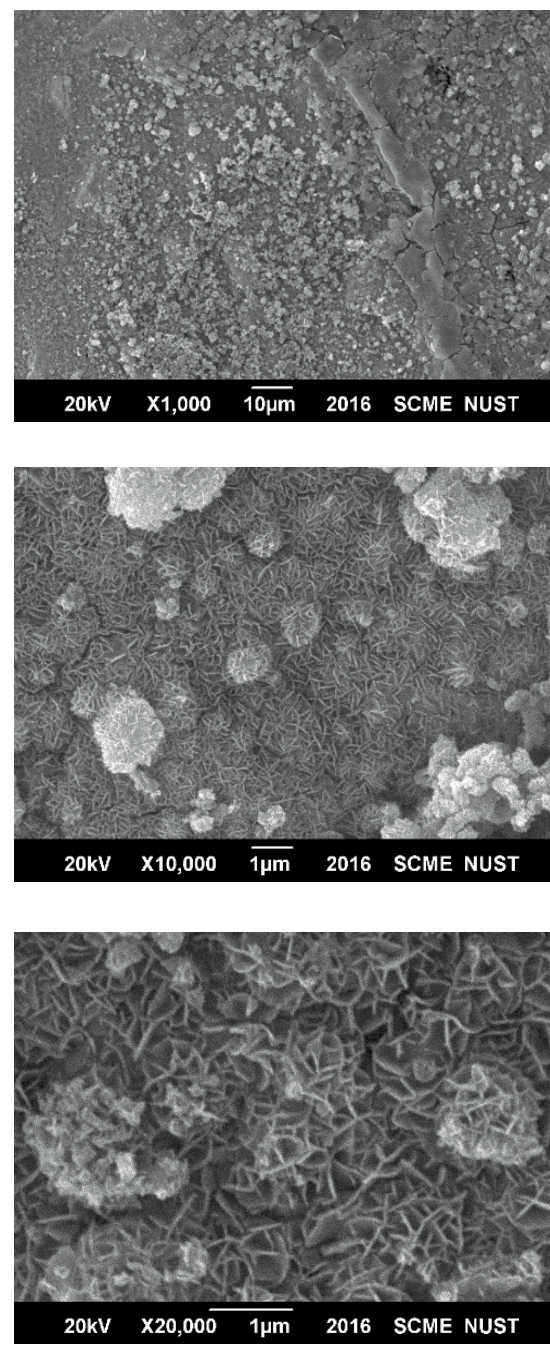

After 1 year dip

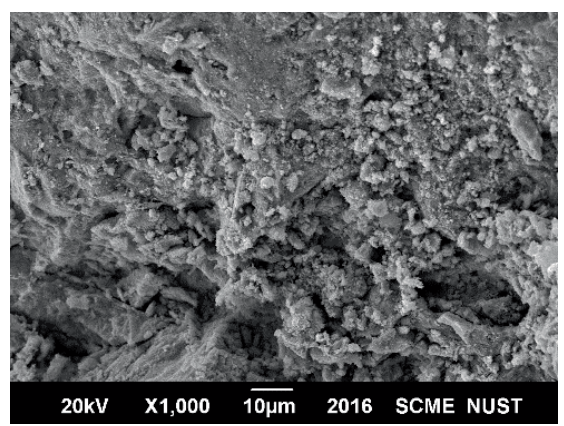

FIGURE 8: SEM images of uncoated and bare samples of mild steel (MS).

was $0.2 \mathrm{~Hz}$ and AC voltage was set at $20 \mathrm{mV}$. Data acquisition sequence is followed as (i) open circuit potential (OCP), (ii) bode plot, and (iii) the Nyquist plot. Appropriate fitting model was applied after the test and when all three graphs were obtained to provide information on the properties such as uncompensated solution resistance $\left(R_{u}\right)$, coating resistance $\left(R_{\text {coat }}\right)$, coating capacitance $\left(C_{c}\right)$, pore resistance $\left(R_{\text {pore }}\right)$, polarization resistance $\left(R_{p}\right)$, and double layer capacitance $\left(C_{d l}\right)$.

\section{Results and Discussion}

3.1. Spectral Analysis of Unsaturated Polyester Resin. Figure 6 shows the transmittance peaks of FTIR spectra of resin. A strong and weak peak at $776 \mathrm{~cm}^{-1}$ and $1004 \mathrm{~cm}^{-1}$ arises because of $\mathrm{C}-\mathrm{H}$ bond present at 1 and 3 positions of benzene ring, respectively, in unsaturated polyester resin. On the other hand, peak at $1306 \mathrm{~cm}^{-1}$ appears because of $-\mathrm{C}=\mathrm{C}$ - group of polyester.

Broad-spectrum transmittance line at $1119 \mathrm{~cm}^{-1}$ shows the presence of $\mathrm{C}-\mathrm{O}-\mathrm{C}$ ester linkage, while peak at $1719 \mathrm{~cm}^{-1}$ is characteristic peak of $-\mathrm{C}=\mathrm{O}$ that confirmed the presence of ester group in polyester resin.

3.2. Spectral Analysis of Fiber-Reinforced Composite. The spectra peaks of cured resin are shown in Figure 7. The peaks at about $2.985 \times 10^{3} \mathrm{~cm}^{-1}$ exhibit sharper trends and peaks which are due to $-\mathrm{CH}=\mathrm{CH}$ - group disappear in polymer- reinforced composite. At $1.408 \times 10^{3} \mathrm{~cm}^{-1}$, a newly developed sharp peak becomes visible in the reinforced polymer composite as seen in the FTIR spectrum. This shows the presence of alkenes and confirmed the participation from $-\mathrm{CH}=\mathrm{CH}-$ alkenes to alkanes group. This indicates that the double bonds in unsaturated resin are the reactive sites that disappear and single bond peak appears. This occurs in the process of curing and change of this group to alkanes during cross-linking process takes place. This is due to the cross-linking polymerization of unsaturated resin to saturated base composite.

3.3. SEM of Uncoated/Bare Sample of Mild Steel. Figure 8 shows SEM micrographs of blisters in mild steel due to corrosion reaction. These blisters are a result of hydrogen penetration 


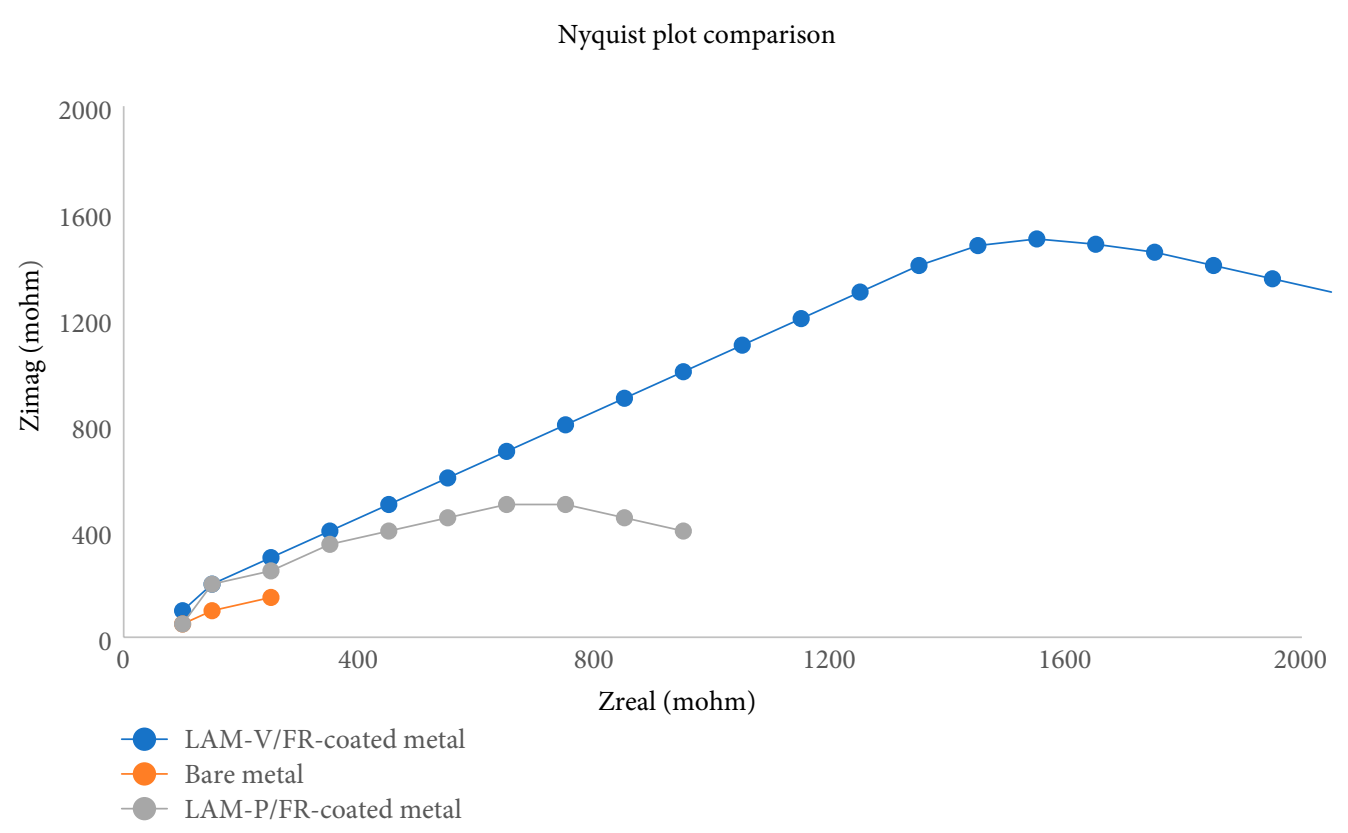

FIGURE 9: Nyquist plots comparison for uncoated, LAM-P/FR, LAM-V/FR-coated MS.

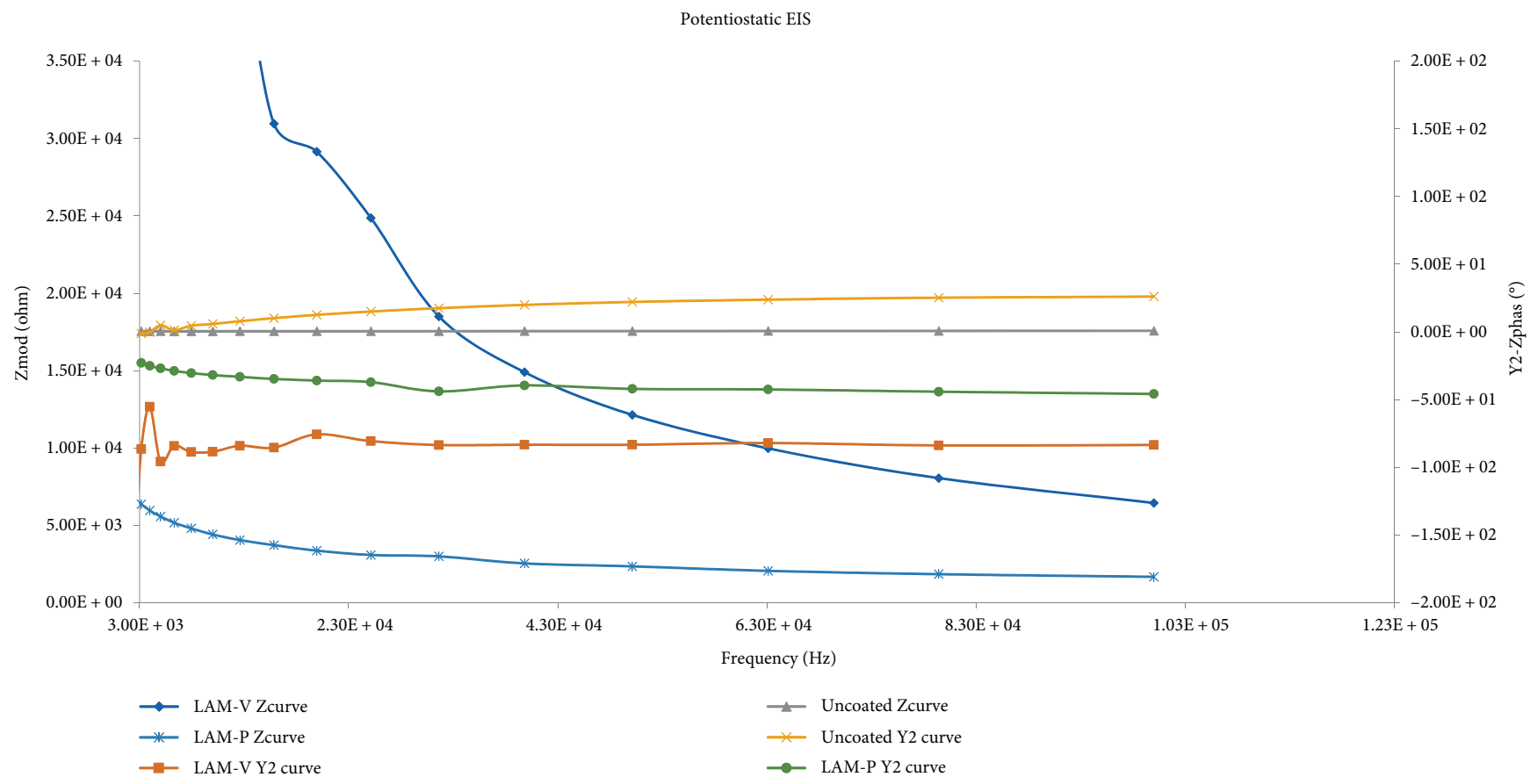

FIGURE 10: Bode plot comparison for uncoated, LAM-P/FR, V-E/FR-coated MS.

into mild steel surface. When mild steel corrodes in the presence of mixed acid $\left(\mathrm{H}_{2} \mathrm{SO}_{4}+\mathrm{HNO}_{3}+\mathrm{H}_{2} \mathrm{O}\right)$, an atomic and molecular hydrogen is formed. If there are voids and spaces, then this atomic hydrogen is collected into these empty holes, so gradually pressure increases and then blistering happened. It also shows that a reaction between ions present in mixed acid solution and mild steel material had taken place. This reaction has caused corrosion products which are shown as featured texture in post-corrosion SEM micrographs, and it is clear that the surface of mild steel was damaged when it was immersed into mixed acidic electrolyte.

\subsection{Nyquist Plots of LAM-P/FR-Coated, LAM-V/FR-Coated,} and Uncoated Mild Steel. All three EIS graphs are discussed in this section for comparison purpose and more detailed analysis. Therefore, all three EIS graphs for uncoated/bare metal, for LAM-P/FR coating, and for LAM-V/FR coating were plotted on the same graph. Figure 9 shows the Nyquist graph 


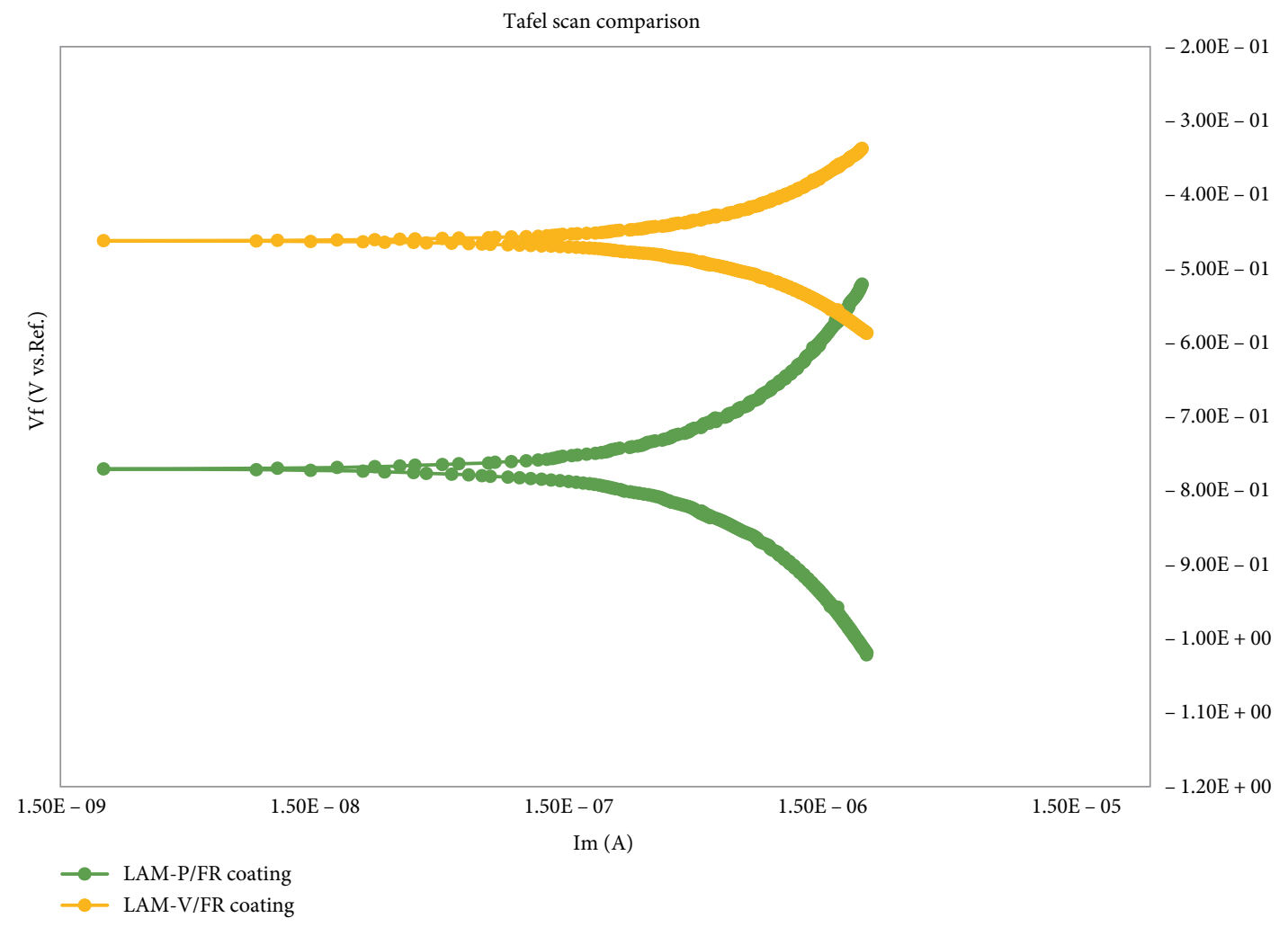

FIGURE 11: Tafel scan comparison for uncoated, LAM-P/FR, LAM-V/FR-coated MS.

TABLE 5: Corrosion rate comparison of LAM-P/FR, LAM-V/FR-coated, and uncoated mild steel.

\begin{tabular}{lccc}
\hline \multicolumn{3}{c}{ Types of coating } \\
\hline Parameter/ & LAM-V/ & LAM-P/ & Uncoated \\
value & FR-coated & FR-coated & sample \\
\hline \multirow{2}{*}{ Beta } & $156.9 \mathrm{e}^{-3} \mathrm{~V} /$ & $147.4 \mathrm{e}^{-3} \mathrm{~V} /$ & $166.5 \mathrm{e}^{-3} \mathrm{~V} /$ \\
& decade & decade & decade \\
$E_{\text {corr }}$ & $-378.3 \mathrm{mV}$ & $-770.7 \mathrm{mV}$ & $-545.9 \mathrm{mV}$ \\
$I_{\text {corr }}$ & $24.98 \mathrm{nA}$ & $207.8 \mathrm{nA}$ & $63.30 \mu \mathrm{A}$ \\
Corrosion rate & $297.1 \mathrm{e}^{-6} \mathrm{mpy}$ & $2.471 \mathrm{e}^{-3} \mathrm{mpy}$ & $28.93 \mathrm{mpy}$ \\
\hline
\end{tabular}

Comparison corrosion rate of LAM-P/FR, LAM-V/FR-coated and uncoated MS in acidic environment $26 \% \mathrm{HNO}_{3}+56 \% \mathrm{H}_{2} \mathrm{SO}_{4}+18 \% \mathrm{H}_{2} \mathrm{O}$.

for all three cases, and as discussed earlier, this observation also suggests that LAM-V/FR provides the highest coating strength before degradation is initiated as compared to the other two graphs, while LAM-P/FR shows enhanced property as compared to bare samples and shows more impedance but less than LAM-V/FR-coating.

The Nyquist plot shows a straight line that goes to 90 degrees from the real axis with continuous increases. This shows that the impedance is continuously increasing and coating is not degraded; as for the case of degradation, a small semi-circle will be formed.

3.5. Bode Plot of LAM-P/FR-Coated, LAM-V/FR-Coated, and Uncoated Mild Steel. Figure 10 shows Bode plots for bare metal sample, LAM-P/FR coating, and LAM-V/FR coating.
The difference is clearly visible that as-expected bare metal shows the least impedance and phase shift which in turn shows that it is more susceptible to corrosion and the impact will be severe in this case due to the absence of protection.

Among the two coatings, LAM-V/FR coatings are showing relatively more strength in acidic environment as compared to LAM-P/FR coating and this is evident from the high value of impedance of this coating and the difference in phase shift is also clearly visible.

The graph here suggests that in acidic environment, LAM-V/FR coatings show more strength against corrosive ions and resist more charges before it is degraded. LAM-P/ FR, however, shows resistance to corrosion and provides protection to some extent which is evident from the difference in graph with the bare metal sample; however, this coating degraded early as compared to LAM-V/FR coating.

3.6. Tafel Scan Comparison. Figure 11 shows Tafel results for LAM-V/FR-coated mild steel and palatal LAM-P/FR-coated mild steel. The difference is clearly visible in comparison graph; as-expected uncoated metal shows more corrosion rate 28.93 of mpy and the impact is shown to be severe in this case due to the absence of protective coatings [23]. In Table 5 , beta values of LAM-V/FR- coated, LAM-P/FR-coated, and uncoated samples are $156.9 \mathrm{e}^{-3} \mathrm{~V} /$ decade, $147.4 \mathrm{e}^{-3} \mathrm{~V} /$ decade, and $166.5 \mathrm{e}^{-3} \mathrm{~V} /$ decade, respectively. There are also $E_{\text {corr }}$ and $I_{\text {corr }}$ values which are $-378.3 \mathrm{mV}$ and $24.98 \mathrm{nA}$ for LAM-V/FR-coating, $-770.7 \mathrm{mV}$ and $207.8 \mathrm{nA}$ for LAM-P/FR coating; on the other hand, values for uncoated sample were $-545.9 \mathrm{mV}$ and $63.30 \mu \mathrm{A}$. Among the two applied coatings, 


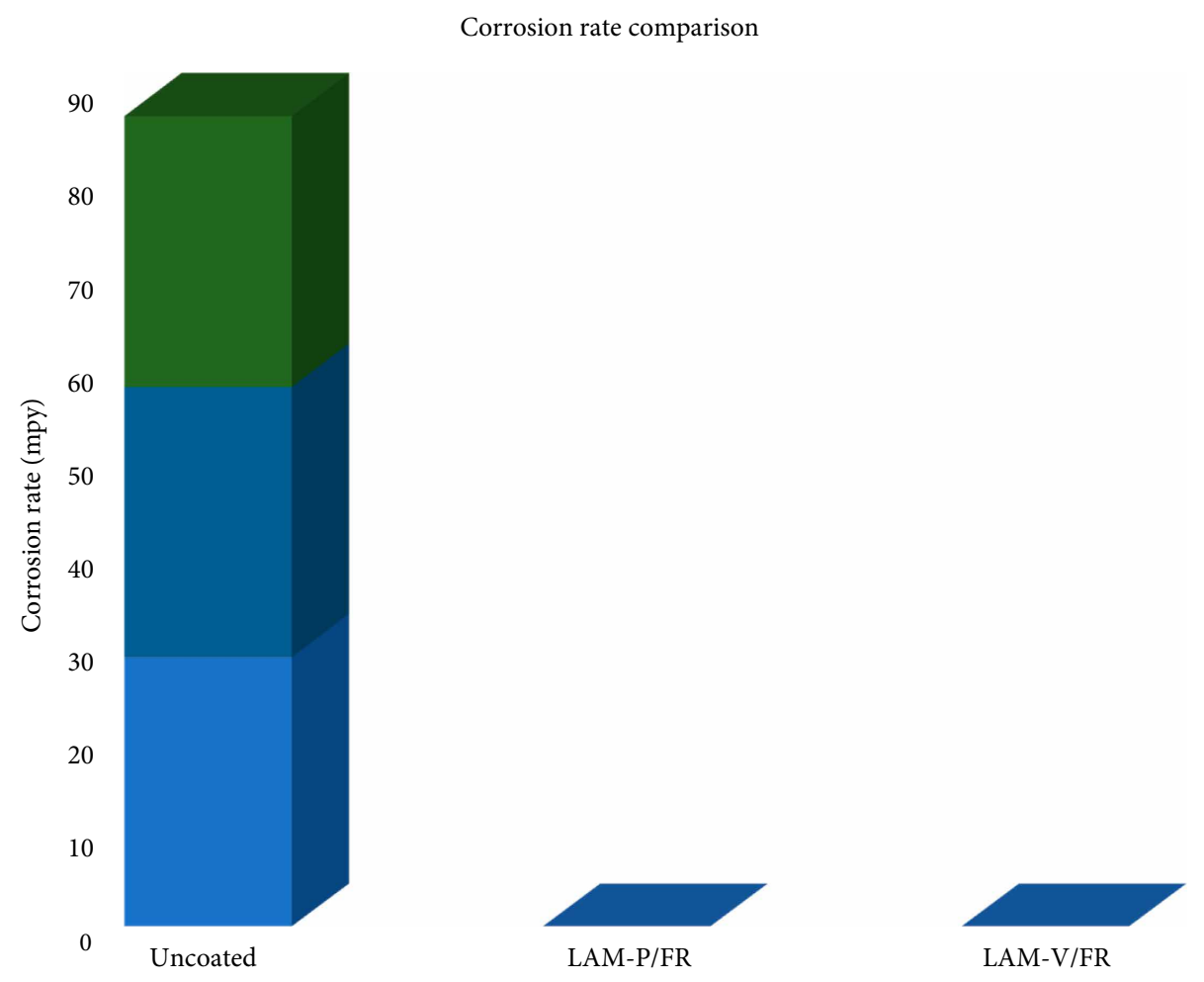

FIGURE 12: Corrosion rate comparison of coated and uncoated metal.

LAM-V/FR coating relatively provided more strength in acidic environment as compared to LAM-P/FR coating as evident from the corrosion rate values. LAM-P/FR-coated metal has corrosion rate of $2.471 \mathrm{e}^{-3} \mathrm{mpy}$, and LAM-V/FRcoated metal has $297.1 \mathrm{e}^{-6} \mathrm{mpy}$ shows more resistance against mixed acid.

3.7. Comparison of Corrosion Rate (Mixed Acid). Corrosion rate is shown in Figure 12 which was observed from Tafel scan using E log I fit model. In this model LAM-V/FR-coated metal has the lowest corrosion rate of $297.1 \mathrm{e}^{-6} \mathrm{mpy}$, LAM-P/ FR-coated metal has a corrosion rate of $2.471 \mathrm{e}^{-3}$ mpy and bare metal has a corrosion rate of $28.93 \mathrm{mpy}$. These results support all the previous results.

3.8. Circuit Modelling Comparison. Figure 13 shows the equivalent model of circuit for a coated metal (LAM-V/FR, LAM-P/FR) which explain the various parts of electrochemical cell and their reaction behaviors. Table 6 shows comparisons of resistance between two coatings by using EIS REAP2CPE fitting values model in acidic solution. The values of $C_{c}, R_{c o r}, R_{p o}$, $C_{\text {cor }}$, and $R_{\text {soln }}$ for LAM-P/FR coating are $27.43 \mathrm{e}^{-9} \mathrm{~F}, 2.073 \mathrm{e}^{-6} \mathrm{~F}$, $4.887 \mathrm{e}^{-3}$ Ohms, $4.369 \mathrm{e}^{3} \mathrm{Ohms}$, and $1.157 \mathrm{e}^{3}$ Ohms, respectively. On the other hand, the values of LAM-V/FR coating of $C_{c}$, $R_{c o r}, R_{p o}, C_{c o r}$, and $R_{\text {soln }}$ are $757.4 \mathrm{e}^{-15} \mathrm{~F}, 1.498 \mathrm{e}^{-9} \mathrm{~F}, 155.6 \mathrm{Ohms}$, $1.923 \mathrm{e}^{3} \mathrm{Ohms}$, and $48.21 \mathrm{Ohms}$, respectively.

The higher value of pore resistance for LAM-V/FR coating as compared to other explains the fact that why this coating has better stability. This is due to higher values of pore resistance, it is attributed that there were lesser percentage of pores that were generated when it interacts with electrolyte in the solution [24].
3.9. Comparison of EIS Fit Model Values (Mixed Acid). Pore resistance and coating capacitance results are provided in Figure 14; the data have been taken from the circuit REAP2CPE fitting model [25]. High pore resistance refers to high stability of coating and means that no pores would be generated when in contact with mixed acid electrolyte. On the other hand, coating capacitance has inverse relation with the total impedance of coating according to the equation below [19].

$$
Z=1 / 2 \pi f C_{c},
$$

where $Z$ is impedance, $f$ is frequency, and $C$ is capacitance. Low fractional area of the metal sample is exposed to acidic electrolyte due to the low impedance. Therefore, the corrosion reaction is suppressed in this case and the opposite happened for the case of polymeric composite coating. Pores play a vital role in increasing or decreasing the corrosion reaction. Coating pore resistance plays a major role in enhancing stability of LAM-V/FR coatings.

For the case of $C_{c}$, it can be observed that LAM-P/FR coating shows more coating capacitance as compared to LAM-V/ FR coating, which explains the reasons of LAM-P/FR coating show less impedance according to Equation (1). As the value of capacitance is increased, the impedance value will decrease. Therefore, LAM-P/FR coating sample has more capacitance which means it is incapable of storing more charges. So, an increase in the charge rate degraded this coating more rapidly as compared to LAM-V/FR coating which is showing lesser coating capacitance value [26].

3.10. Physical Appearance Test of LAM-V/FR Coating Immersed in Mixed Acid. Figure 15 shows experimental 


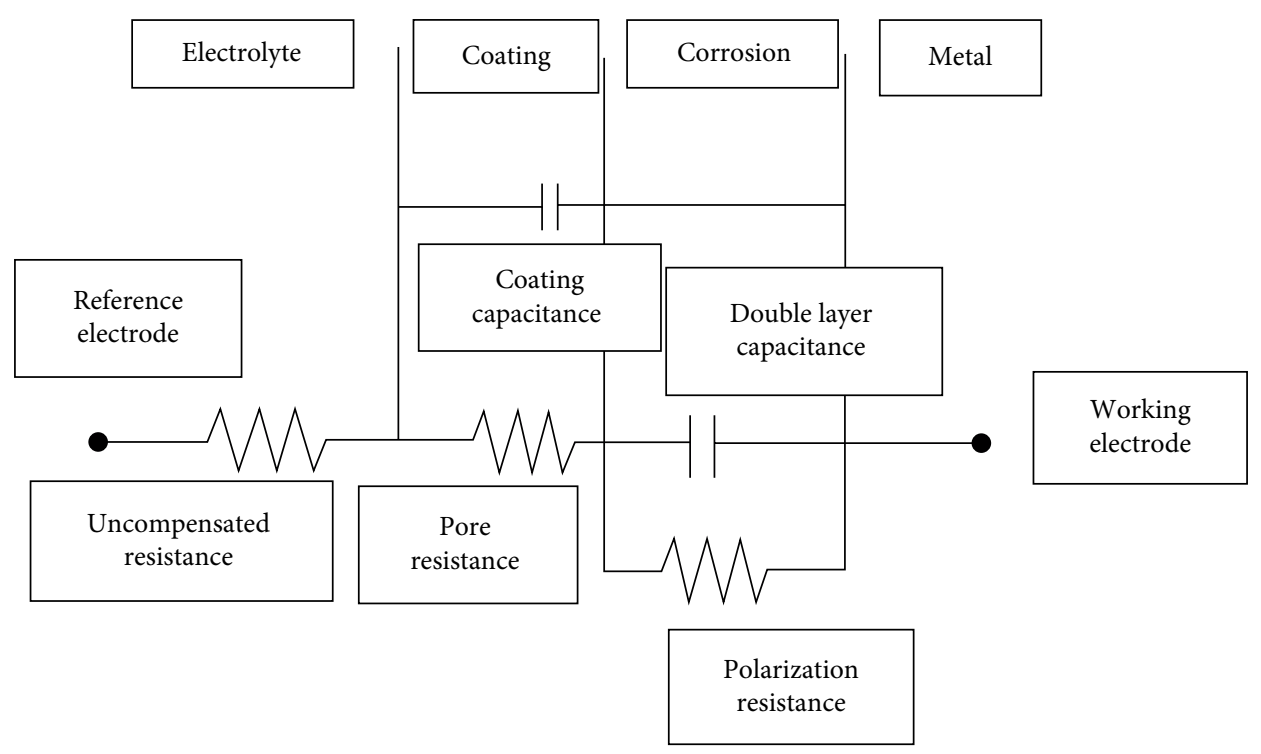

FIgURE 13: Coated metal (REAP2CPE) circuit.

TABLE 6: Comparison EIS REAP2CPE model fitting values for both coating in acidic solution.

\begin{tabular}{|c|c|c|c|}
\hline \multicolumn{2}{|c|}{ LAM-P/fiber mat coating } & \multicolumn{2}{|c|}{ LAM-V/fiber mat coating } \\
\hline$R_{\text {soln }}$ & $1.157 \mathrm{e}^{3} \mathrm{Ohms}$ & $R_{\text {soln }}$ & $48.21 \mathrm{Ohms}$ \\
\hline$R_{\text {cor }}$ & $4.369 \mathrm{e}^{3} \mathrm{Ohms}$ & $R_{c o r}$ & $1.923 \mathrm{e}^{3} \mathrm{Ohms}$ \\
\hline$R_{p o}$ & $4.887 \mathrm{e}^{-3} \mathrm{Ohms}$ & $R_{p o}$ & $155.6 \mathrm{Ohms}$ \\
\hline$C_{c o r}$ & $2.073 \mathrm{e}^{-6} \mathrm{~F}$ & $C_{c o r}$ & $1.498 \mathrm{e}^{-9} \mathrm{~F}$ \\
\hline$C_{c}$ & $27.43 \mathrm{e}^{-9} \mathrm{~F}$ & $C_{c}$ & $757.4 \mathrm{e}^{-15} \mathrm{~F}$ \\
\hline
\end{tabular}

$R_{\text {pore }}$ Comparison of coated metal

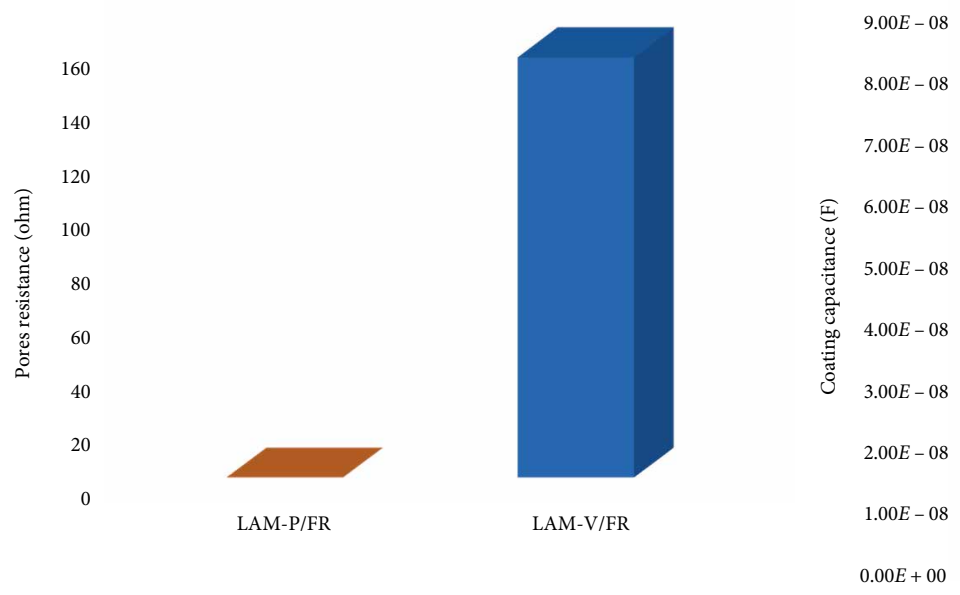

$C_{c}$ Comparison of coated metal

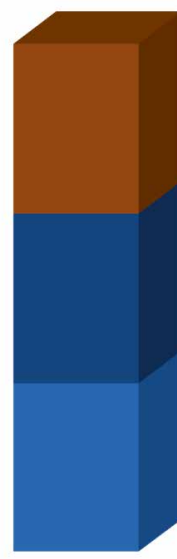

LAM-RF/P

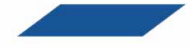

LAM-V/FR

Figure 14: $P_{R}$ and $C_{C}$ values comparison between LAM-V/FR and LAM-P/FR.

progress over 5 months log with respect to time. LAM-V/ FR coatings were immersed in mixed acid with $56 \% \mathrm{H}_{2} \mathrm{SO}_{4}$, $26 \% \mathrm{HNO}_{3}$ and $18 \% \mathrm{H}_{2} \mathrm{O}$ composition by weight for 1 month, 3 months, and 5 months. Coating degradation was not observed and; $0.33 \%$ weightloss was observed after 5 months. 
LAM-V/FR immersed 1 months

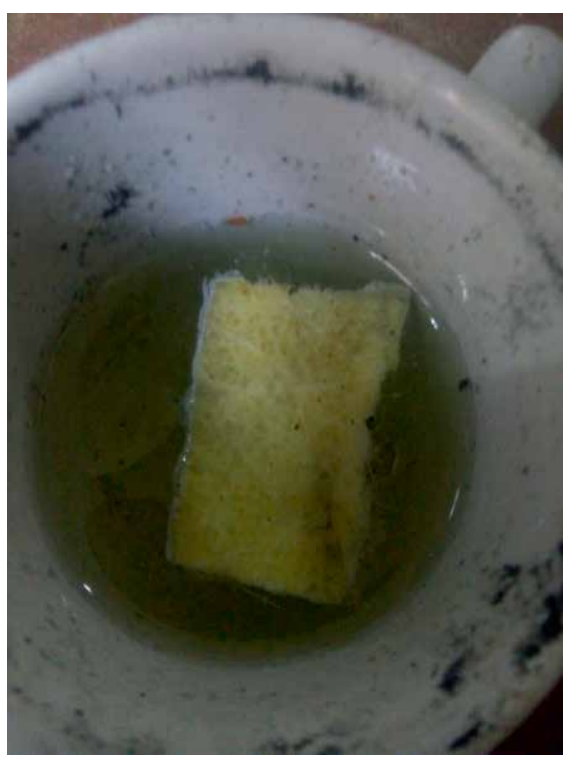

Immersed 3 months

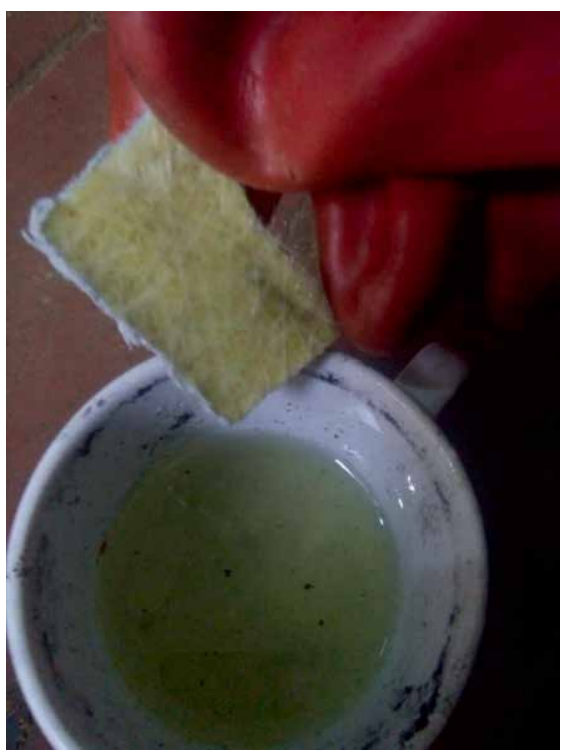

Immersed 5 months

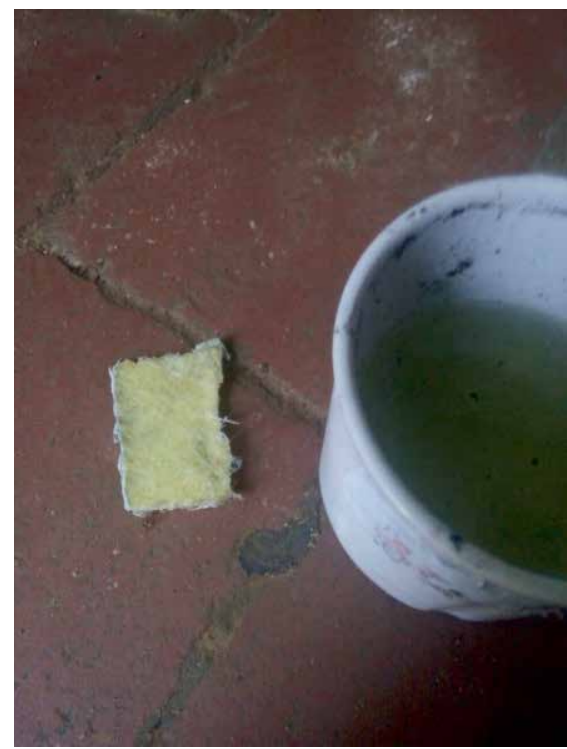

FIGURE 15: Surface morphological analysis of LAM-P/FR and V-E/FR coatings.

LAM-P/FR before dip

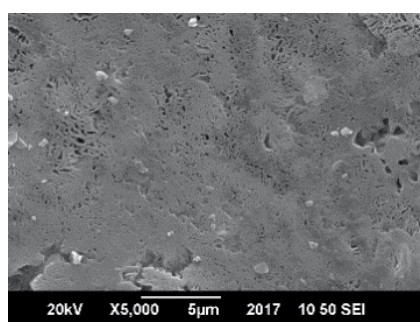

LAM-P/FR before dip

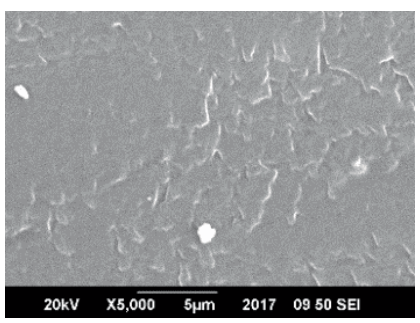

After dip

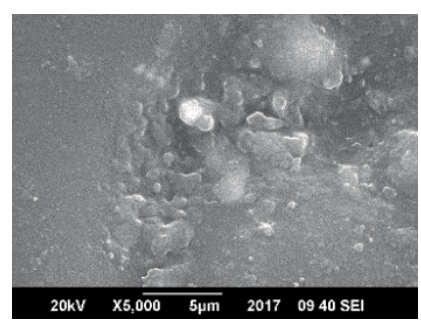

After dip

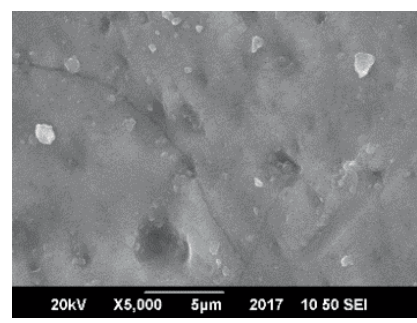

Edge before dip

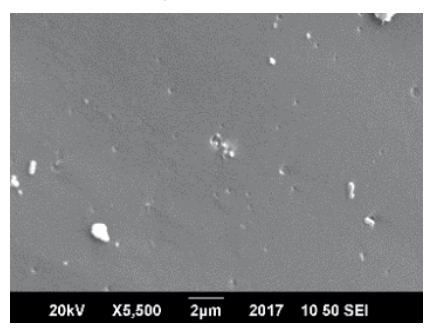

Edge before dip

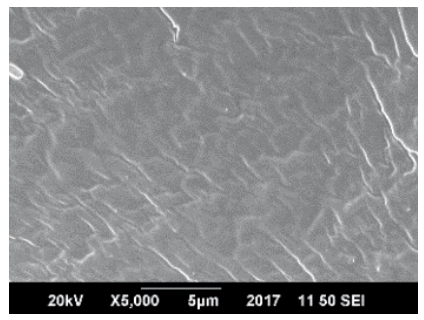

Edge after dip

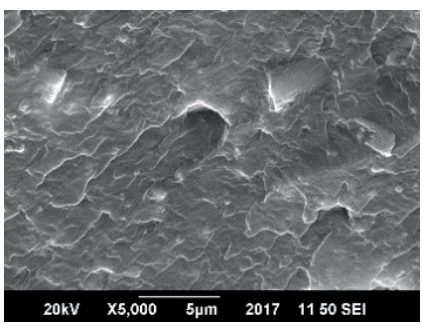

Edge after dip

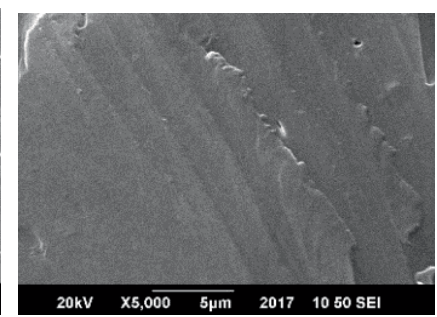

FIGURE 16: SEM of LAM-P/FR and LAM-V/FR coatings before and after immersion in mixed acid.

Weight loss $=9.697-9.693=0.032 \mathrm{gm}(0.33 \%)$.

\subsection{Surface Morphological Analysis of LAM-P/FR and V-E/} FR Coatings. Surface morphology of LAM-P/FR and LAM-V/ FR coatings result shown in Figure 16 was studied by scanning electron microscopy before and after immersion in mixed acid solution. Results indicated that LAM-P/FR coating surface was slightly damaged, while LAM-V/FR coating surface seen smooth with no scratches was observed when immersed in mixed acid; it means that it is more effective than the first one. The physical appearance test was also applied at the edges of both coatings; it also confirms the superiority of LAM-V/FR coating.

\section{Conclusions}

Anticorrosive polyester-based composite coatings were developed and applied on mild steel mixed acid storage tank containing varying compositions of sulfuric acid and nitric acid to provide anticorrosive solutions. These are advanced technological polymer coatings that are capable to inhibit the redox reactions with the purpose to prevent corrosion on mixed acid storage tank through the application of appropriate polyester coatings on their surface and structures that are widely used in chemical industries where these acids are being kept stored. The surface of mild steel was coated by protective polymer coatings. Customized storage tanks of mild steel were 
coated with anticorrosive coating made from laminate vinyl fiber-reinforced and laminate palatal fiber-reinforced p-4. Various coatings compositions were explored based on esters. Electrochemical impedance spectroscopy (EIS) and Gamry potentiostat Tafel scan analyses tools were used, and scanning electron microscopy (SEM) was conducted to investigate the surface morphology of these coatings. The applied polymer-based composite coatings provided excellent corrosion resistance in both laminate palatal fiber-reinforced (LAM-P/ FR) and laminate vinyl fiber-reinforced (LAM-V/FR) coatings condition and reduction in corrosion rate. The study suggests that significant corrosion controlled can be achieved through the employment of these corrosion protection coatings.

\section{Data Availability}

The datasets generated during and/or analyzed during the current study are available from the corresponding author on reasonable request.

\section{Conflicts of Interest}

The authors declare that there is no conflict of interest regarding the publication of this paper.

\section{Acknowledgments}

The authors would like to acknowledge the support provided by NUST Research Directorate to conduct this research. Equipment support and procurement through Higher Education Commission (HEC) Pakistan, NRPU program grant No. 3526 and grant No. 6020 is acknowledged.

\section{References}

[1] D. Talbot and J. Talbot, "Corrosion science and technology", Materials Science \& Technology.

[2] S. Lower, "Electrochemical Corrosion," 2016, (Simon fraser University), https://chem.libretexts.org/Textbook_Maps/ General_Chemistry/Book\%3A_Chem1_(Lower)/16\%3A_ Electrochemistry/24.08\%3A_Electrochemical_Corrosion.

[3] "BS 4360 Weldable Steel Plate," 2017, http://gangsteel.net/ product/Carbon/Q/BS-4360/2012/0914/43A.html.

[4] R. E. Melchers, "Effect of nutrient-based water pollution on the corrosion of mild steel in marine immersion conditions," Corrosion, vol. 61, no. 3, pp. 237-245, 2005.

[5] M. A. Quraishi and J. Rawat, "Inhibition of mild steel corrosion by some macrocyclic compounds in hot and concentrated hydrochloric acid," Materials Chemistry and Physics, vol. 73, no. 2-3, pp. 118-122, 2002.

[6] H. Yun, J. Li, H.-B. Chen, and C.-J. Lin, "A study on the N-, Sand $\mathrm{Cl}$-modified nano- $\mathrm{TiO}_{2}$ coatings for corrosion protection of stainless steel," Electrochimica Acta, vol. 52, no. 24, pp. 6679$6685,2007$.
[7] G. X. Shen, Y. C. Chen, and C. J. Lin, "Corrosion protection of 316 $\mathrm{L}$ stainless steel by a $\mathrm{TiO}_{2}$ nanoparticle coating prepared by solgel method," Thin Solid Films, vol. 489, no. 1-2, pp. 130-136, 2005.

[8] M. H. Nazir, A. Saeed, and Z. Khan, "A comprehensive predictive corrosion model incorporating varying environmental gas pollutants applied to wider steel applications," Materials Chemistry and Physics, vol. 193, pp. 19-34, 2017.

[9] B. Wessling, "Passivation of metals by coating with polyaniline: corrosion potential shift and morphological changes," Advanced Materials, vol. 6, no. 3, pp. 226-228, 1994.

[10] A. F. Frau, R. B. Pernites, and R. C. Advincula, "A conjugated polymer network approach to anticorrosion coatings: poly(vinylcarbazole) electrodeposition," Industrial \& Engineering Chemistry Research, vol. 49, no. 20, pp. 9789-9797, 2010.

[11] M. H. Nazir, Z. A. Khan, A. Saeed, and K. Stokes, "A model for cathodic blister growth in coating degradation using mesomechanics approach," Materials and Corrosion, vol. 67, no. 5, pp. 495-503, 2016.

[12] S. Ananda Kumar, K. Shree Meenakshi, T.S. N.Sankaranarayanan, and S. Srikanth, "Corrosion resistant behaviour of PANI-metal bilayer coatings," Progress in Organic Coatings, vol. 62, no. 3, pp. 285-292, 2008.

[13] M. D. Shittu, J. O. Olawale, M. O. Adeoye, K. M. Oluwasegun, K. M. Adebayo, and O. O. Ige, "Investigation of corrosion resistance of polystyrene as an inhibitor in hydrochloric and tetra-oxo sulphate VI acids," International Journal of Materials and Chemistry, vol. 4, no. 1, pp. 9-13, 2014.

[14] X. Meng, J. A. Syed, H. Lu, and S. Tang, "Enhanced corrosion protective PANI-PAA/PEI multilayer composite coatings for 316 SS by spin coating technique," Applied Surface Science, vol. 325, pp. 160-169, 2015.

[15] A. Ammar, M. Shahid, M. Ahmed, M. Khan, A. Khalid, and Z. Khan, "Electrochemical study of polymer and ceramic-based nanocomposite coatings for corrosion protection of cast iron pipeline," Materials, vol. 11, no. 3, p. 332, 2018.

[16] A. Ghadami, M. Ehsani, and H. A. Khonakdar, "Vinyl ester/ glass flake nanocomposites: an overview of chemical and physical properties," Journal of Composite Materials, vol. 48, no. 13, pp. 1585-1593, 2014.

[17] S. Barbhuiya and M. Choudhury, "Nanoscale characterization of glass flake filled vinyl ester anti-corrosion coatings," Coatings, vol. 7, no. 8, p. 116, 2017.

[18] S. Waigaonkar, B. J. C. Babu, and A. Rajput, "Curing studies of unsaturated polyester resin used in FRP products," Indian Journal Engineering Materials Science, vol. 18, no. 1, pp. 31-39, 2011.

[19] D. Loveday, P. Peterson, B. Rodgers, and G. Instruments, "Loveday 2004 EIS," 2004.

[20] L. R. Faulkner and J. A. Bard, Fundamentals and Applications, Wiley, New York, 2nd edition, 2000.

[21] C. Zoski, Ed., Handbook of Electrochemistry, Elsevier, Amsterdam, Netherlands, 1st edition, 2006.

[22] M. G. Fontana and N. D. Greene, Corrosion Engineering, McGrawHill Education (pvt) Ltd, New York, 1987.

[23] M. Jayalakshmi, N. Kalyanaraaman, and R. Pitchappan, "Hepatitis B virus genetic diversity: disease pathogenesis," in Viral Replication, World's largest Science Technology \& Medicine Open Access Book Publisher. 
[24] R. Hedman, "Computational design of lysozyme binders," 2011, https://www.ibg.uu.se/digitalAssets/162/c_162814-1_3-k_ mindre-fil-rapport-rikard-hedman.pdf.

[25] M. Fontana, Corrosion Engineering, McGraw Hill Education (India) private limited, 3rd edition (1900) edition, 2005.

[26] J. G. Han, S. H. Ahn, Y. S. Choi, and J. G. Kim, "A study on corrosion resistance characteristics of PVD Cr-N coated steels by electrochemical method," Surface and Coatings Technology, vol. 150, no. 2-3, pp. 319-326, 2002. 


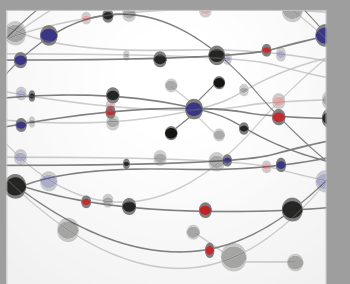

The Scientific World Journal
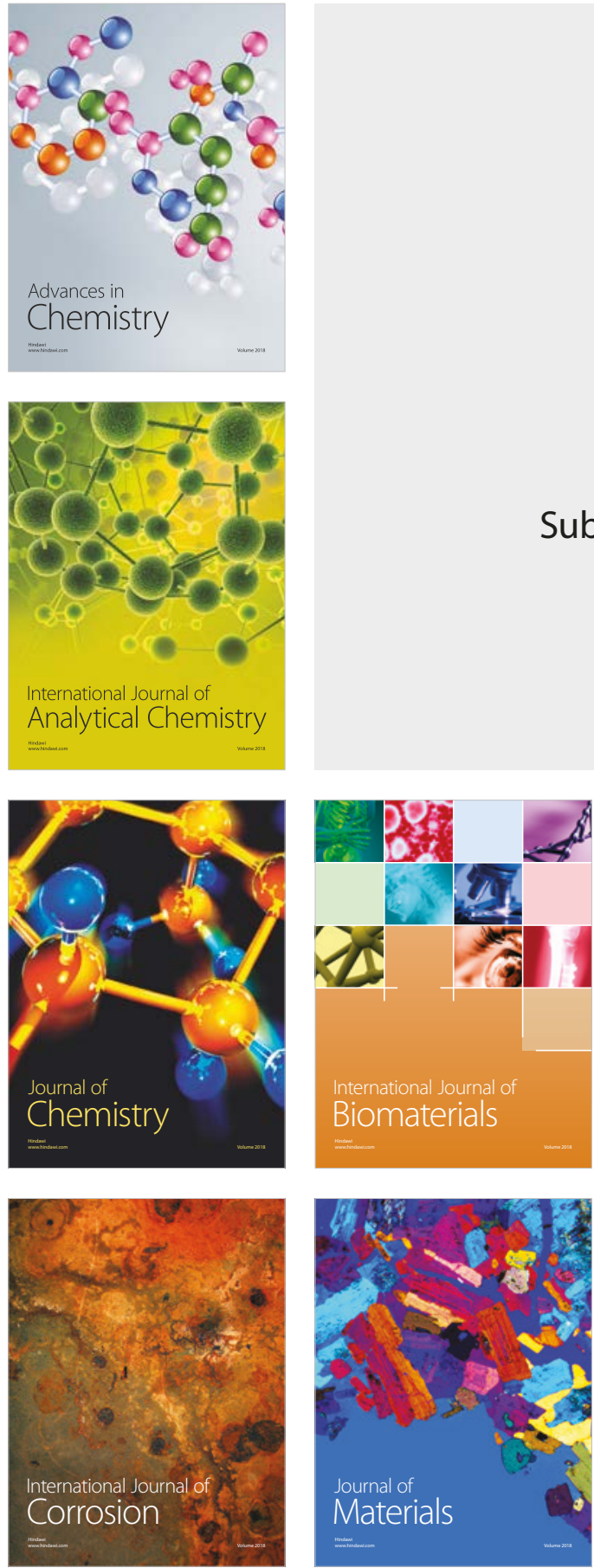

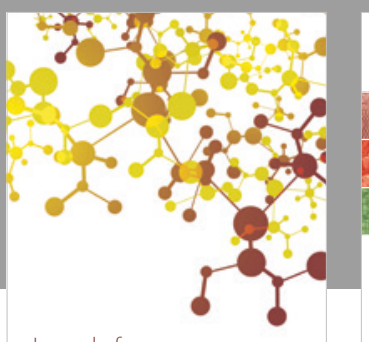

Journal of

Applied Chemistry
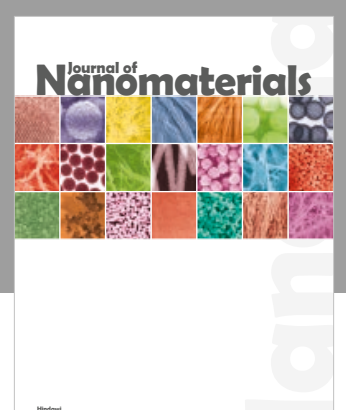

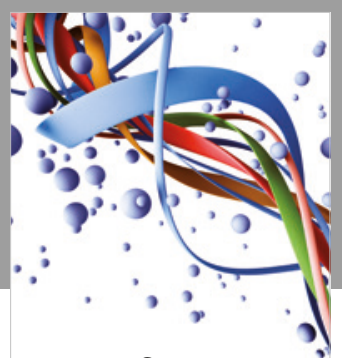

Scientifica

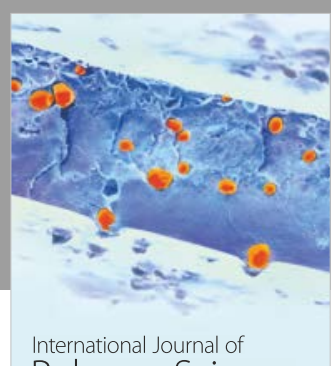

Polymer Science

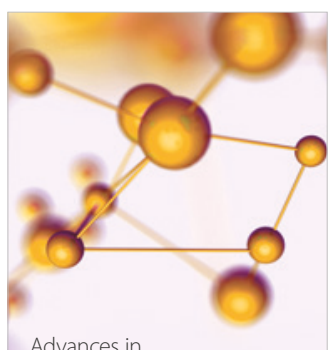

Physical Chemistry
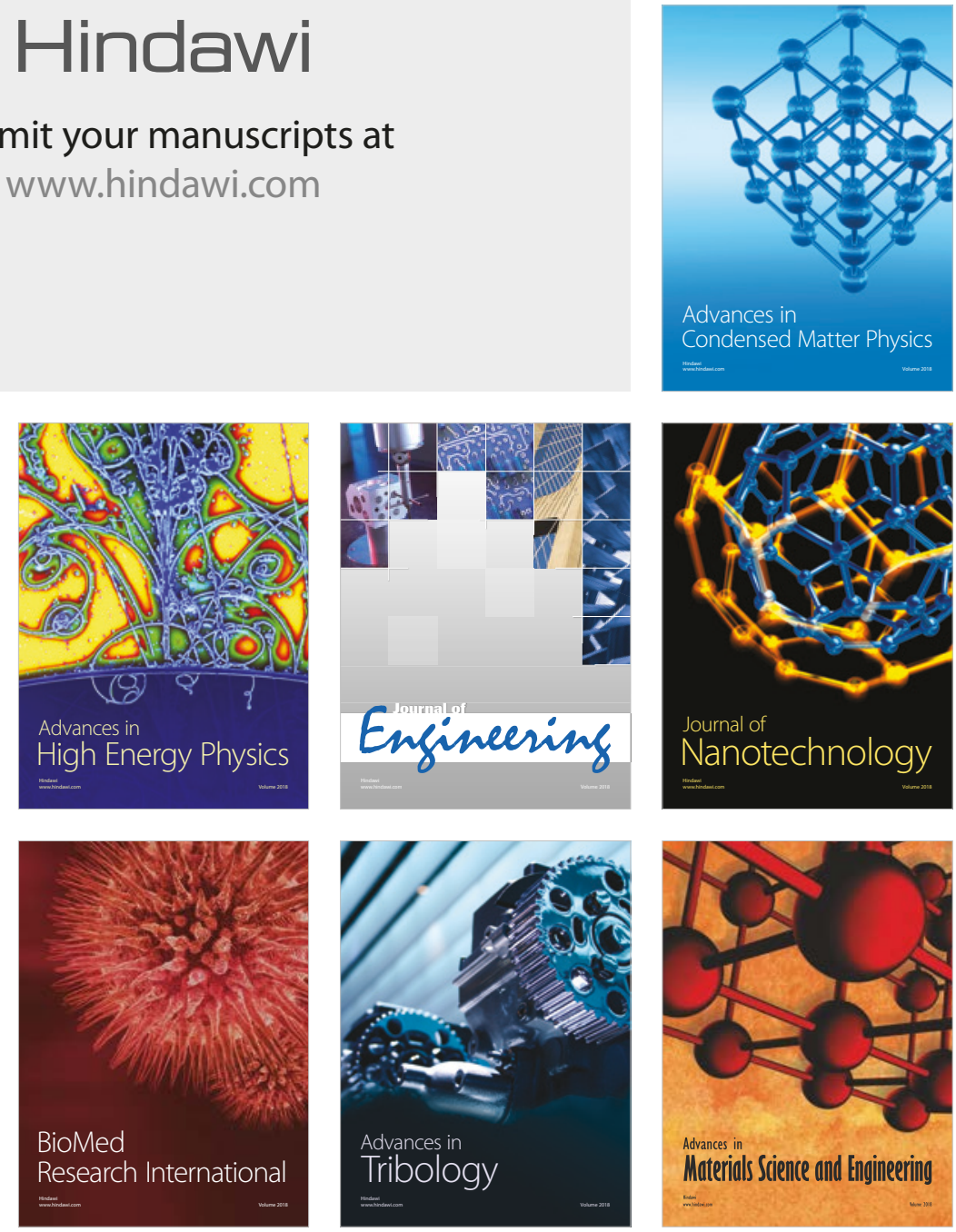